\title{
MЭМС-датчики Murata: инновационные технологии для точных измерений
}

\begin{abstract}
Следуя своему девизу Innovator in electronics, компания Murata Manufacturing предлагает инновационные технологические решения в различных областях: от керамических конденсаторов и индуктивностей до радиочастотных модулей и силовых устройств. Среди продукции компании особое место занимают МЭМСдатчики - акселерометры, гироскопы и инклинометры, которые отличаются высокой точностью, стабильностью и надежностью. На выставке electronica 2018, прошедшей в ноябре прошлого года в Мюнхене, Murata представила новые решения в области МЭМС-устройств для мониторинга состояния конструкций и сооружений, автомобильных систем безопасности и медицинских приборов. Рассмотрим особенности МЭмС-технологии компании Murata, перспективные области применения и новинки, предложенные компанией.
\end{abstract}

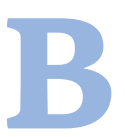

МЭМС-датчиках Murata применяется простой и надежный принцип емкостного детектирования, основанный на измерении емкости, которая меняется при колебании проводящихтел внутри устройства. Например, основные элементы акселерометров - пружина, чувствительная масса и опора. Пружина соединяет массу с опорой. При изгибе пружины в результате движения датчика расстояние между телом и чувствительной массой меняется пропорционально ускорению. При уменьшении расстояния емкость повышается, и электрический ток протекает по направлению к датчику, а когда расстояние увеличивается - наоборот. Таким образом, датчик преобразует ускорение тела в электрический ток.

Благодаря высоким характеристикам МЭМС-датчиков, основанных на технологии емкостных измерений, устройства оптимально подходят для детектирования даже небольших изменений в движении. Чувствительный элемент MЭмС-датчиков Murata изготовлен из монокристаллического кремния и стекла. Это обеспечивает датчику высокую надежность, точность, стабильность во времени и при изменении температуры. Как правило, чувствительный элемент способен выдерживать ускорение более 50 000g.

Из-за недостаточно продуманной конструкции МЭМСдатчики зачастую уязвимы для паразитных сигналов, вызванных вибрацией при эксплуатации прибора. Благодаря инновационной конструкции МЭМС-датчики Murata виброустойчивы, невосприимчивы к паразитным сигналам, их параметры отличаются высокой стабильностью. Устройства защищены от воздействия атмосферных явлений силиконовым гелем, что обеспечивает высокую надежность в условиях влажной окружающей среды и при цикличном изменении температуры. Кроме того, прочный чувствительный элемент с частотной характеристикой со сверхкритическим затуханием обеспечивает высокие характеристики в жестких условиях эксплуатации. Симметричная конструкция чувствительных элементов датчиков позволяет улучшить линейность этих устройств.

Высокие характеристики датчиков Murata достигаются в первую очередь благодаря применению технологии 3D MEMS, впервые внедренной финской компанией VTI Technologies, которая в 2012 году была приобретена компанией Murata. Сегодня это отделение Murata носит название Murata Electronics Oy. Основу технологии составляют базовые процессы, применяемые при производстве полупроводниковых ИС: использование кремниевых пластин в качестве исходного материала, осаждение тонких пленок, фотолитография для формирования структур (рис. 1). Однако создание трехмерной МЭМС-структуры потребовало введения в технологический маршрут дополнительных операций и процессов.

В 3D МЭМС-устройствах пружина, инерционное тело и конденсаторы вытравливаются в кремниевой пластине путем метода сухого травления - глубокого реактивного ионного травления. По сравнению с жидкостным травлением этот метод обеспечивает более высокую плотность упаковки структуры и точность размеров. Для контроля процесса травления в вертикальном направлении и обеспечения электрической изоляции кремниевых структур Murata использует пластины кремния-на-изоляторе (КнИ) или кремния-на-изоляторе суглублениями. Это позволяет достичь большей гибкости при проектировании топологии структуры и обеспечить хорошую изоляцию активных областей с малыми паразитными емкостями.

Интегральные схемы обычно пассивируются при помощи диэлектрических слоев, нанесенных на поверхность пластины. Такой подход невозможен в МЭМС-устройствах, 


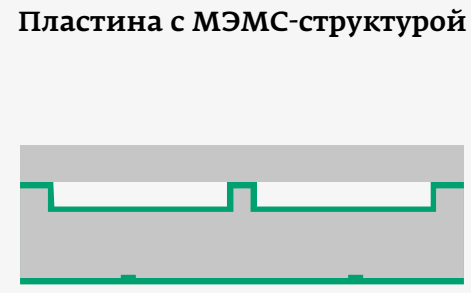

КнИ-пластина с углублениями

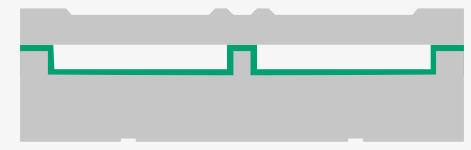

Формирование выемок

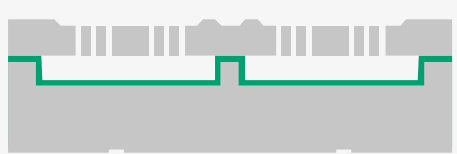

Формирование МЭМС-структуры
Защитная пластина

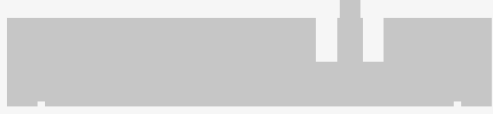

Травление переходных отверстий

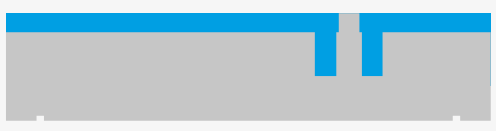

Нанесение стекла

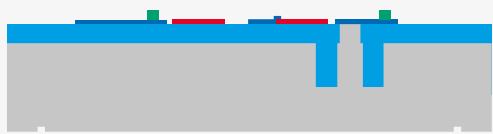

Нанесение тонких пленок
Объединенная структура

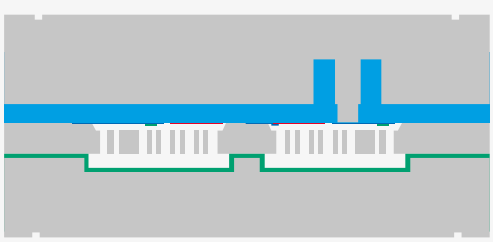

Анодная сварка

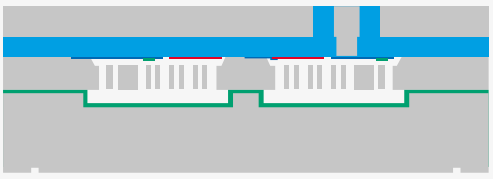

Шлифовка защитной пластины

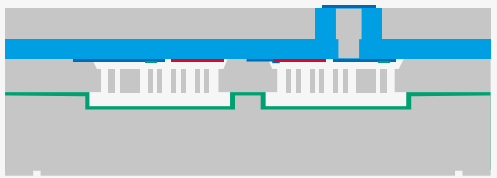

Металлизация

\section{Рис. 1. Процесс формирования структуры 3D-MЭМС}

поскольку внутренние структуры должны оставаться подвижными. В МЭМС-технологии защита устройства обеспечивается путем приварки кпластине с 3D MЭМс-структурами другой пластины, которая называется крышкой или защитной пластиной (рис. 2). Murata использует в качестве защитной пластины гетерогенные структуры из кремния и стекла, для создания которых применяется патентованная технология.

Защитная пластина и 3D MЭМС-пластина соединяются посредством еще одного тщательно контролируемого процесса - анодной сварки стекла и кремния (см. рис. 1). За счет приложения электрического поля и температуры обеспечивается прочное соединение на атомном уровне. В результате достигаются герметичная защита внутренних МЭМс-структур и высокая надежность устройства.

Электрическое соединение с МЭМС-устройством должно быть реализовано через защитную пластину. Murata одной из первых стала использовать для этого сквозные переходные отверстия (through-silicon via - TSV). TSV - отверстие в пластине, заполненное кремнием, изолированным от пластины слоем стекла. Стекло обеспечивает высокое сопротивление изоляции и малую паразитную емкость между переходными отверстиями, что повышает точность и снижает энергопотребление. Поскольку TSV формируются путем травления, они могут быть размещены в любом месте защитной пластины (в отличие от проволочного монтажа, когда топологию устройства нужно проектировать так, чтобы проволочный вывод подходил точно к краю кристалла).
После предварительного зондового тестирования МЭМС-структур на сандвич из МЭМС- и защитной пластины устанавливают кристалл заказной ИС для обработки сигналов с датчика, используя технологию flip-chip. Затем выполняют резку пластин и финальное тестирование с последующей калибровкой датчиков. Пространство вокруг ИС заливают пластиком, устойчивым к ударам и вибрации. Для дополнительной защиты пластикового корпуса используют силиконовый гель и сверху крепят металлическую крышку. Получаемые МЭМС-устройства готовы к эксплуатации в жестких условиях эксплуатации. При этом, МЭМС-датчики Murata отличаются высокой точностью и стабильностью характеристик в широком диапазоне рабочих температур.

Благодаря высоким характеристикам и надежности MЭМС-датчики Murata подходят для применения в ряде ответственных приложений с повышенными требованиями к качеству компонентов.

Акселерометры и гироскопы Murata востребованы в системах обеспечения безопасности автомобиля, включая системы динамической стабилизации, предупреждения водителя (ADAS), помощи при спуске (HAS); подвеску с электронной регулировкой плавности движения; управление трансмиссией; электронный стояночный тормоз и др. В промышленности МЭМС-датчики Murata успешно используются в самых разных областях, в частности в сельскохозяйственной и строительной технике, крупногабаритном обрабатывающем оборудовании, робототехнике, навигационном оборудовании, 


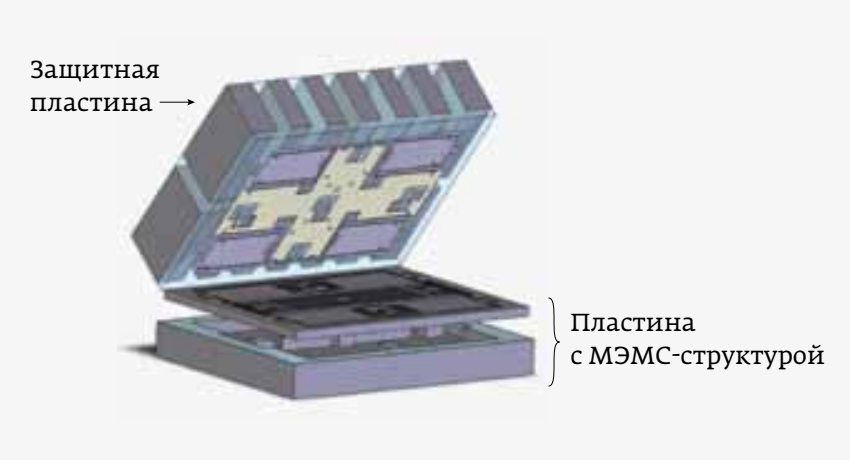

Рис. 2. Структура МЭМС-датчика Murata

системах контроля наклона в весовом оборудовании, в авиационных приборах и системах.

МЭМС-инклинометры незаменимы для мониторинга состояния конструкций и сооружений в качестве детекторов возможных деформаций, что позволяет своевременно приступить к ремонтным работам - задолго до того, как возникнет реальная опасность для людей. Появляется возможность прогнозировать срок эксплуатации объектов, долгосрочно планировать инвестиции в инфраструктуру. Кроме того, конструкции, состояние которых необходимо контролировать, зачастую находятся в труднодоступных для обслуживающего персонала местах. Свести к минимуму количество визитов бригад технического обслуживания можно, если выбрать решение, которое сохраняет точность и стабильность длительное время в среде, где внешние условия, такие как температура и влажность, меняются в широких диапазонах. Именно для таких условий идеально подходят устройства Murata.

Кроме того, МЭМС-датчики Murata нашли широкое применение в здравоохранении, в частности в кардиостимуляторах, высокоточном медицинском оборудовании, таком какхирургические столы, протезы, диагностическая аппаратура, системы мониторинга состояния пациента и др.

Одно из наиболее совершенных МЭМС-устройств, выпущенных компанией Murata за последнее время, - 3-осевой акселерометр серии SCA3300, предназначенный для широкого спектра промышленных и автомобильных приложений (рис. 3).

Миниатюрный МЭМс-датчик поставляется в пластиковом 12-выводном корпусе с двухрядным расположением выводов для поверхностного монтажа с габаритами 7,6×8,6×3,3 мм. Пользователю доступен выбор диапазона измерения: $\pm 1,5 g, \pm 3 g$ или $\pm 6 g$. Акселерометры серии SCA3300 обеспечивают линейность не менее $\pm 1 \mathrm{~g}$ в диапазоне измерений $\pm 1 \mathrm{~g}$ и не менее $\pm 15 \mathrm{Mg}$ - в диапазоне измерений $\pm 6 g$, плотность шума не превышает 37 мкg $/ \sqrt{\Gamma ц}$. Механическое демпфирование чувствительного элемента датчика обеспечивает высокую точность измерений в жестких условиях с повышенным уровнем вибраций.

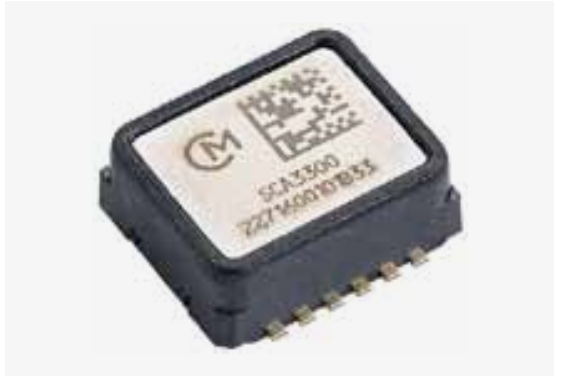

Рис. 3.

3-осевой акселерометр серии SCA3300

Диапазон питающего напряжения акселерометра от 3 до 3,6 В, при этом ток потребления не превышает 1,2 мА, что делает возможным его применение в устройствах с батарейным питанием. В режиме пониженного энергопотребления потребляемый ток снижается до 0,5 мА. Для обмена данными датчик оснащен стандартным SPI-интерфейсом.

Датчик SCA3300 отвечает требованиям стандарта AEC-Q100 для автомобильных компонентов. Диапазон рабочих температур акселерометра составляет от -40 до $125^{\circ} \mathrm{C}$. Устройство содержит ИС для обработки сигналов, включающей АЦП. Датчик оснащен широким набором функций обеспечения безотказной работы (мониторинг внутреннего опорного сигнала, проверка контрольных сумм при обмене данными, отслеживание насыщения сигнала и выхода его за границы диапазона). В акселерометр SCA3300 встроена функция самодиагностики - запатентованная система непрерывного самотестирования, которая в каждом цикле измерений проверяет корректность функционирования всего сигнального тракта: от МЭМС-датчика до схемы обработки сигнала.

Сфера применения акселерометра SCA3300 чрезвычайно широка: системы выравнивания и позиционирования, гиростабилизаторы для тяжелого оборудования, навигационные системы, автоматически управляемые механизмы, строительная техника. Перспективные области использования устройств - автомобильные системы обеспечения безопасности, в частности система предупреждения водителя (ADAS), системы автономного вождения и интеллектуального управления трансмиссией (рис. 4). Дополнительный возможный вариант - контроль наклона в весовом оборудовании.

Еще одно интересное устройство Murata - комбинированный датчик серии SCC2000, включающий 3-осевой акселерометр и гироскоп (рис. 5). Ключевыми приложениями для этих МЭМС-датчиков также являются автомобильное и промышленное оборудование. Устройства, предназначенные для жестких условий эксплуатации, отличаются минимальными в своем классе зависимостью от температуры и чувствительностью к ударам, а также наиболее низкой нестабильностью смещения нуля.

Они содержат акселерометр диапазона low-g с датчиком угловой скорости, измеряемой по оси Х либо по оси Z, 


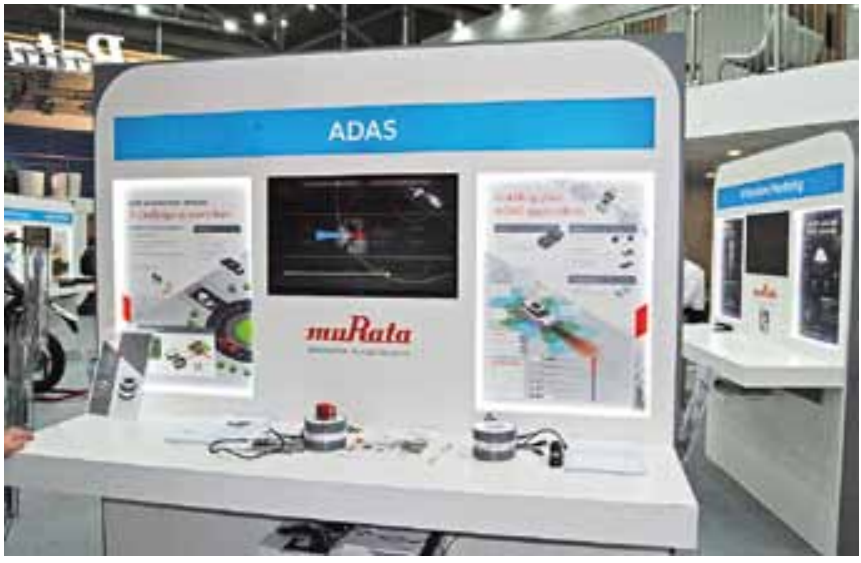

Рис. 4. Демонстрация системы ADAS на основе MЭMCдатчиков Murata на выставке electronica 2018

а также 32-битный цифровой SPI-интерфейс. Датчик оснащен программно выбираемым фильтром нижних частот на 10 или 60 Гц, который конфигурируется через SPI-интерфейс. Диапазон измерений гироскопа составляет $\pm 125 \%$ или \pm 300 \%, 3-осевого акселерометра - \pm 2 или $\pm 6 g$. Типичная величина температурного дрейфа акселерометра составляет $\pm 6 \times 10^{-3} \mathrm{~g}$ для датчиков с диапазоном $\pm 2 \mathrm{~g}$ и $\pm 12 \times 10^{-3} \mathrm{~g}$ - для датчиков с диапазоном $\pm 6 \mathrm{~g}$. Температурный дрейф гироскопа обычно находится в пределах $\pm 0,5 \%$ для моделей с диапазоном $\pm 125 \%$. Типичная кратковременная нестабильность смещения нуля гироскопов составляет 1\% для приборов с диапазоном $\pm 125 \%$ с и осью измерений X и 2\% - для приборов с диапазоном $\pm 125^{\circ}$ / с и осью измерений Z.

Устройства серии SCС2000 выпускаются в 24-выводных пластиковых корпусах для поверхностного монтажа типа SOIC габаритами 15,00×112,10×14,35 мм. Датчики отвечают требованиям стандарта безопасности транспортных средств ISO26262 и автомобильного стандарта AEC-Q100. Эта комплексная платформа для измерения ускорений и угловых скоростей по всем трем осям позволяет создавать одноплатные измерительные системы с шестью степенями свободы.

Датчики серии SCC2000 предназначены для широкого спектра ответственных приложений, в частности для активных и пассивных автомобильных систем обеспечения безопасности, таких как система динамической стабилизации, система помощи при спуске (HAS), активное рулевое управление, адаптивный круиз-контроль для современных систем помощи водителю (ADAS). Благодаря надежной конструкции датчики серии SCC2000 также подходят для систем, эксплуатируемых в жестких условиях, например для сельскохозяйственных машин, строительной техники или крупногабаритного обрабатывающего оборудования. Еще одна сфера применения устройств - инерциальные навигационные системы.

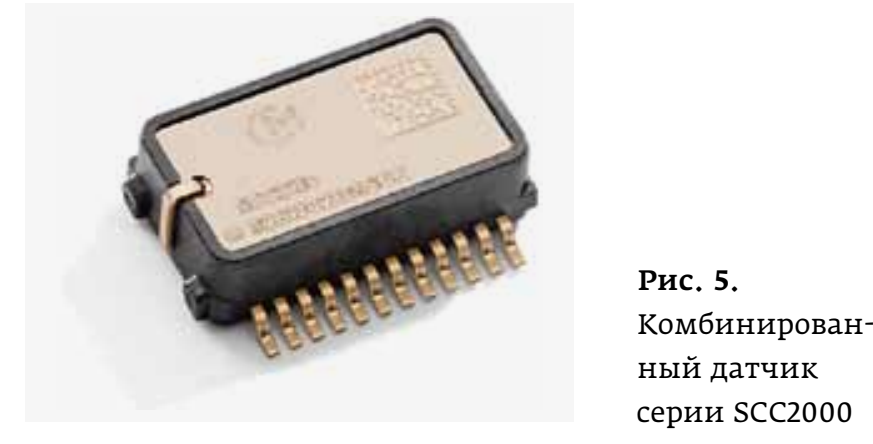

На выставке electronica 2018 в ноябре прошлого года компания Murata анонсировала новинку - МЭМС-инклинометр серии SCL3300 для измерения угла наклона по трем осям, оснащенный цифровым выходом в градусах угла отклонения. Разрешение по углу на выходе устройства составляет 0,0055 \%M3P. В SCL3300 предусмотрена возможность выбора четырех режимов измерения, которые можно использовать для оптимизации характеристик датчика в зависимости от требований приложения.

Устройство содержит ИС для обработки сигналов с цифровым SPI-интерфейсом, поэтому отпадает необходимость во внешнем АЦП, можно минимизировать габариты, энергопотребление и сложность системы. Встроенный преобразователь данных ускорения в угол наклона позволяет упростить проектное решение, использовать простое и надежное ПО. Датчик оснащен встроенными функциями самодиагностики.

Диапазон измерения угла наклона датчика SCL3300 coставляет $\pm 90^{\circ}$, что упрощает измерительное ПО и эксплуатацию устройства. Диапазон рабочих температур - от -40 до $125^{\circ} \mathrm{C}$ с типовым дрейфом смещения менее \pm 10 мg во всем диапазоне температур. Датчик отличается ультранизкой плотностью шума на уровне 0,001 \% $\sqrt{Г ц, ~ ч т о ~ о б е с-~}$ печивает высокую разрешающую способность измерительной системы.

SCL3300, работающий от напряжения питания в диапазоне от 3 до 3,6 В, подходит для систем с батарейным питанием, в частности приложений Интернета вещей, благодаря типовому току потребления в спящем режиме всего 3 мкА. Устройство предлагается в компактном пластиковом 12-выводном корпусе для поверхностного монтажа габаритами 8,6×7,6×3,3 мм, который отвечает требованиям директивы RoHS.

Ключевые области применения инклинометра SCL3300: мониторинг состояния труднодоступных конструкций и сооружений, компенсация угла наклона весов, робототехника, системы позиционирования и навигации, управление механизмами. Кроме того, устройство можно использовать везде, где нужны точные измерения угла наклона, требуется компенсация отклонения от вертикали или сохранение горизонтального положения, например для выравнивания механизмов и машин. 